\title{
Impact of lockdown-related reduction in anthropogenic emissions on aerosol characteristics in the megacity, Bengaluru
}

\author{
A. Ajay ${ }^{1,2, *}$, K. Krishna Moorthy ${ }^{3}$, S. K. Satheesh ${ }^{2,3}$ and G. Ilavazhagan ${ }^{1}$ \\ ${ }^{1}$ Hindustan Institute of Technology and Science, Chennai 603 103, India \\ ${ }^{2}$ Divecha Centre for Climate Change, Indian Institute of Science, Bengaluru 560 012, India \\ ${ }^{3}$ Centre for Atmospheric and Oceanic Sciences, Indian Institute of Science, Bengaluru 560 012, India
}

Continuous analytical measurements of the loading and optical properties of near-surface aerosols over the megacity Bengaluru, in south India, are examined for the impact of the national lockdown (LD) associated with COVID-19 pandemic. The near total shutdown of rail, road, and air traffic as well as total closure of most of the business establishments and IT industry, especially during the first phase of the $L D$, is found to dramatically reduce black carbon (BC) abundance. Within one week of the first week of the $L D$ phase 1 (LD1), the ambient BC concentration at the urban centre came down to levels comparable to those reported for remote rural locations, primarily due to $>60 \%$ reduction in $\mathrm{BC}$ from fossil fuel $\left(\mathrm{BC}_{\mathrm{ff}}\right)$ emissions. On the other hand, $\mathrm{BC}$ from biomass burning $\left(B_{w b}\right)$ did not show any conspicuous impact. Consequently, the fraction of $\mathrm{BC}_{\mathrm{wb}}$ to $\mathrm{BC}$ more than doubled and the spectral absorption coefficient increased from $\sim 1.15$ to $\sim 1.4$. The single scattering albedo increased from its prevailing mean value 0.66 before $L D$ to 0.74 during LD1 and then gradually decreased to 0.68 with increasing relaxations on vehicular traffic. The results reveal the unequivocal role of vehicular emissions in impacting the aerosol loading and their optical properties over Bengaluru. The study also shows how the environment responded to the gradual relaxations in the subsequent phases of $\mathrm{LD}$. It is interesting to note that a few spells of strong rainfall towards the fourth phase of the LD impacted the aerosols non-selectively leading to sharp decrease in all the quantities. However, owing to the non-selective nature of the washout this large reduction in loading did not impact the single scattering albedo, unlike the case with the LD.

Keywords: Black carbon, COVID-19 lockdown, scattering coefficients, single scattering albedo.

\section{Introduction}

THE close link between anthropogenic activities and the concentration of aerosols and greenhouse gases in the atmosphere as well as the increasing trends in their con-

*For correspondence. (e-mail: ajay1@iisc.ac.in) centration has well been recognized. There has also been concerted efforts to delineate the impacts due to longlived climate forcing agents (such as $\mathrm{CO}_{2}, \mathrm{CH}_{4}$ ) and short-lived climate forcing agents (such as aerosols including $\mathrm{BC}$, oxides of nitrogen $\left(\mathrm{NO}_{x}\right)$ and ozone) even to the extent of implementing global policies to limit the global warming trend ${ }^{1-3}$. Nevertheless, experimental quantification of the extent to which the human activities impact the environment remained almost elusive due to the ever persisting and increasing nature of it. Isolated case studies, specific to certain locations, though have been reported ${ }^{4,5}$, the results are substantially influenced by other activities with human linkages, which persisted even in those study regions and their neighbourhood. The national level lockdown (LD) to combat the community spread of the COVID-19 pandemic, and the concurrent similar actions across the globe by several countries provided a unique opportunity to examine the environmental impacts of human activities on a wider canvass. This article reports the impacts on some of the short-lived climate forcing agents (such as aerosols - composite as well as absorbing carbonaceous species) in the urban centre of the megacity of Bengaluru $\left(13.01^{\circ} \mathrm{N}, 77.34^{\circ} \mathrm{E}\right.$ and $920 \mathrm{~m} \mathrm{amsl}$ ), for the first time from primary measurements, making use of the unique opportunity provided by the national LD for an extended period of time (24 March to 21 May; in phased manner) associated with the pandemic.

\section{Lockdown in brief}

The LD, considered in this article, has been widespread, prolonged and in phases. The national LD was enforced on 24 March 2020, initially for a period of 3 weeks until to 14 April. During this period there was total suspension of traffic (road, rail, air and marine) across entire India, except for essential services. In addition, all kinds of small, large and medium scale industries, central and state government offices, educational institutions, commercial establishments, places of spiritual and cultural gathering remained shut. Even family functions were restricted, and people were advised to stay indoors. It has 


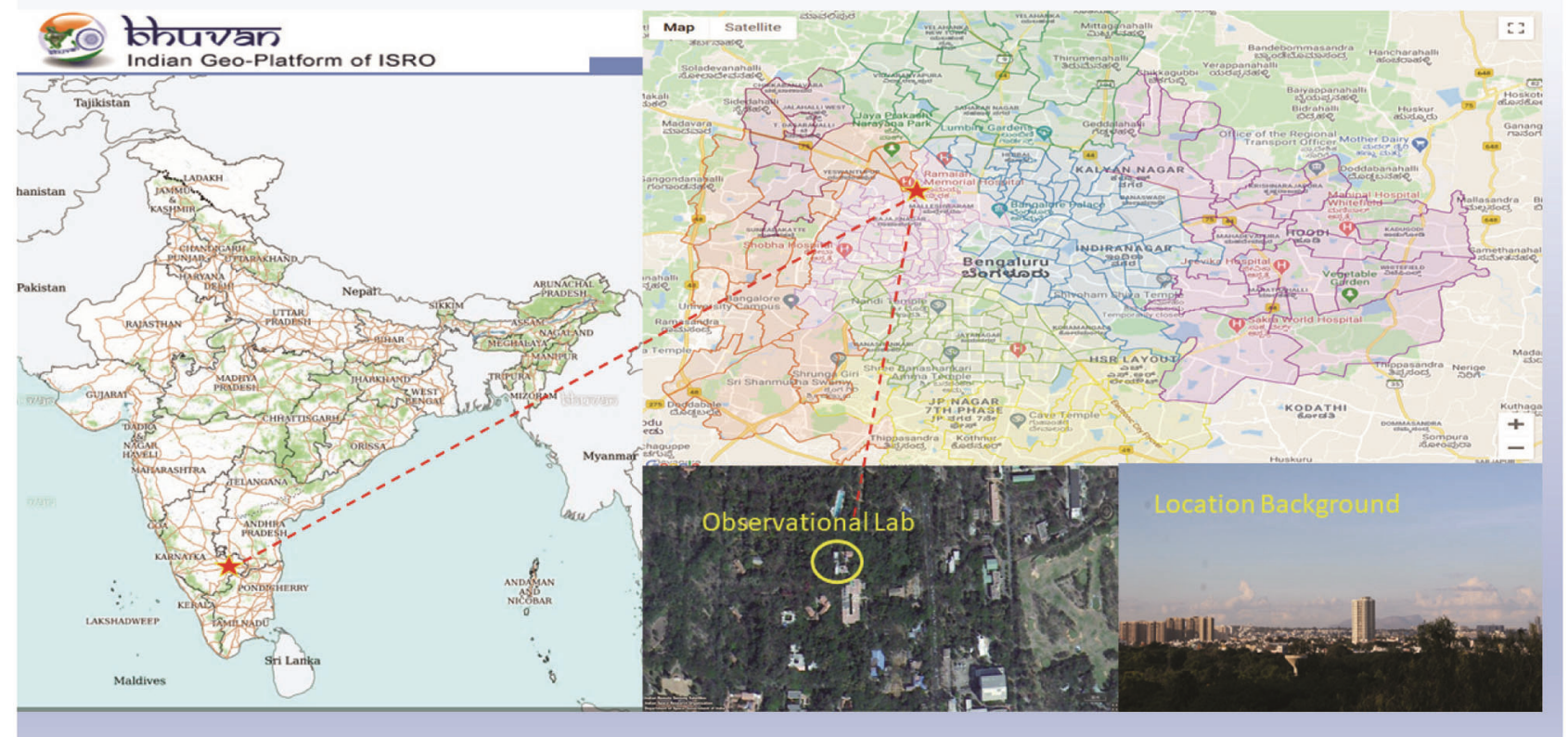

Figure 1. Geographical location of the sampling site. A satellite view of observational lab at IISc campus (yellow circle) and the urban background are also shown.

been almost a complete stoppage of anthropogenic activities, except for domestic activities. During the second phase of lock down (LD2) from 15 April to 3 May 2020, though air and rail traffic as well as public transport remained suspended, some relaxations have been provided in movement of goods, essential items, medical equipment and private vehicles (for emergency purposes) though inter-district and inter-state movements remained largely curtailed. During the third phase of LD (LD3) from 4 May to 17 May restrictions, especially on movement, were further relaxed and more flexibility was provided to states for managing microlevel details. Vehicular movement was permitted from 7 am to $7 \mathrm{pm}$. Small and medium scale industries were opened; all government offices and IT companies were permitted to operate at around $30 \%$ capacity. Commercial complexes and public transport remained largely suspended. Road, rail, and air traffic were operated in limited extent to repatriate stranded citizen and migrant labourers. The fourth phase (LD4) from 18 May to 31 May saw further relaxation, yet certain restrictions on traffic, large business and commercial establishments continued. All academic institutions remained closed during the entire period from LD1 to LD4. Prior to the national LD, there was a slowing down of activities in Bengaluru, with all educational institutions being closed from 14 March (mini shutdown).

\section{Sampling location}

The observational data used in this study have been collected from the main campus of the Indian Institute of
Science (IISc) $\left(13.01^{\circ} \mathrm{N}, 77.34^{\circ} \mathrm{E} ; 920 \mathrm{~m}\right.$ amsl), Bengaluru; located in the city centre ${ }^{6}$. The geographical location in the backdrop of the urban area of Bengaluru and the surrounding topography are shown in Figure 1. Bengaluru is one of the fastest growing megacities of India; located in the central part of the South Indian peninsula. More details of the city and its prevailing meteorology are available in several earlier publications ${ }^{6}$ and are not repeated, except that the study period (January to May 2020) has been climatologically not different.

The $2174 \mathrm{~km}^{2}$ area of Bengaluru urban conglomerate has more than $50 \%$ of the land being used for residential, industrial and commercial purposes, and only $24 \%$ for agricultural purposes. It is the third most populated city in India, with a population of 9.62 million (census 2010 11) and projected to reach about 12.3 million by 2019 ; with a population density is $4,378 \mathrm{~km}^{2}$. Bengaluru is a major global IT hub. It stands second after New Delhi in its population of automobiles; which has crossed 8 million in 2019; the rate of increase for the last 12 years (as per records of the Regional Transport Office) is shown in Figure 2 and constitute a major source of emissions. Other major human activities include construction, rail and air traffic and activities related to large commercial establishments, besides domestic emissions.

\section{Measurement of data}

The data used in this study comprise regular and continuous measurement of the mass concentration of aerosol black carbon and spectral scattering coefficients of 
composite aerosols; both near the surface. Measurements are carried out by drawing air from the top of the laboratory building, $\sim 10 \mathrm{~m}$ above ground level. BC measurements are carried out using a 7-Channel Aethalometer (model AE-33 of Magee Scientific) ${ }^{7}$ with time resolution of $1 \mathrm{~min}$. This instrument measures the attenuation light passing through its particle laden filter tape at seven different wavelengths $(370,470,520,590,660,880$ and $950 \mathrm{~nm}$ ). The attenuation measured at $880 \mathrm{~nm}$ wavelength is used to estimate $\mathrm{BC}$ concentration ${ }^{8}$. AE-33 uses the dual spot technique to account for the particle loading on the filter ${ }^{9}$, multiple scattering correction is internally done using correction factor $c=1.9^{10}$ and thus gives nearreal-time concentration of total $\mathrm{BC}$ and its constituents in terms $\mathrm{BC}$ originating fossil fuel burning $\left(\mathrm{BC}_{\mathrm{ff}}\right)$ and those from biomass (wood) burning $\left(\mathrm{BC}_{\mathrm{wb}}\right)^{10,11}$.

Total scattering and back scattering of composite aerosols have been measured regularly at 3 wavelengths $(450$, $532,632 \mathrm{~nm}$ ) using an integrating Nephelometer model number (IN102 from Air-Photon) ${ }^{12}$, operated at a flow rate of 5 LPM and time-base of $20 \mathrm{sec}$; in which configuration the instrument measured scattering due to aerosols without any size selection. Correction for angular truncation error has been carried out following the procedure described by Anderson and Ogren ${ }^{13}$. These data formed the primary database for the current study.

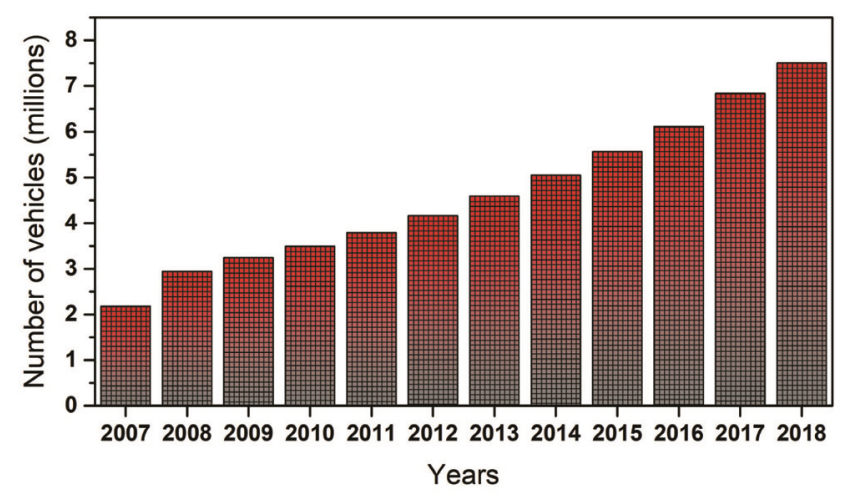

Figure 2. Total number of registered vehicles based on Regional Transport Office Bengaluru for the period 2007-2018.

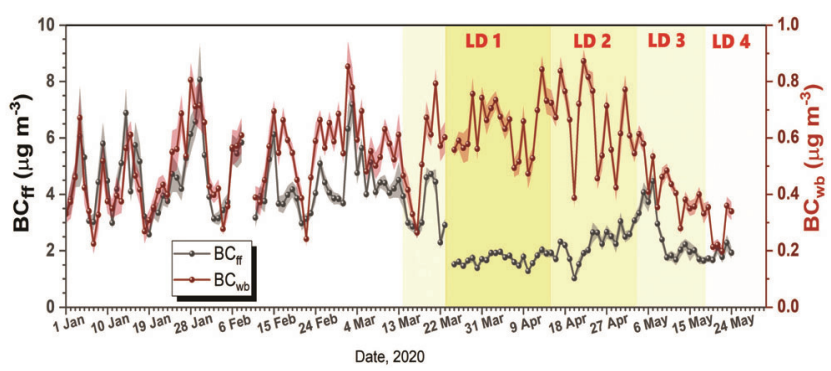

Figure 3. Time series of daily mean values of black carbon (BC) from fossil fuels $\left(\mathrm{BC}_{\mathrm{ff}}\right.$ black colour) and wood burning $\mathrm{BC}_{\mathrm{wb}}$ (red colour) during study period. Shaded area over the lines represents the respective standard errors.
Aerosol optical depth (AOD) measurements using ground-based instruments were discontinued due to closing down of the laboratory for longer duration (prior to LD1 to LD3). Satellite data are not considered for analysis because of the known uncertainties arising due to the uncertainty of the ground reflectance and its variations ${ }^{14}$.

\section{Results and discussions}

In the following, we first examine the time series of the measured parameters from January 2020 followed by the impact on derived optical properties.

\section{Black carbon aerosols}

Time series of the mass concentrations of $\mathrm{BC}_{\mathrm{ff}}$ and $\mathrm{BC}_{\mathrm{wb}}$ is shown in Figure 3, starting from 1 January 2020. The different LD phases including the minor shutdown (15 March to 23 March) specific to Bengaluru are shown by different shades on the same figure. The figure reveals the following striking features:

(1) Nearly a steady level of high $\mathrm{BC}_{\mathrm{ff}}$ (mean around $4.46 \pm 0.17 \mu \mathrm{g} \mathrm{m}^{-3}$; which is more or less same as the climatological mean value for this season for Bengaluru $\left(4.11 \pm 0.16 \mu \mathrm{g} \mathrm{m}^{-3}\right)$ ) from January until about 10 March; superposed with periodic fluctuations arising out of variations in the source strengths $^{6}$. This is followed by a conspicuous decreasing trend until 22 March and a dramatic fall by more than $60 \%$ to $\sim 1.6 \mu \mathrm{g} \mathrm{m}^{-3}$ by 24 March; a value very close to those reported for a remote rural location in the peninsular region ${ }^{15}$.

(2) The $\mathrm{BC}_{\mathrm{ff}}$ concentration continued at this subdued level for about 3 weeks until 15 April, with very little day-to-day variations.

(3) In the subsequent phases of LD (2,3 and 4), we can clearly see that the concentration of $\mathrm{BC}_{\mathrm{ff}}$ and its day-to-day variability are increasing, the increase being more dominant in LD3 and LD4.

(4) More interestingly, the $\mathrm{BC}_{\mathrm{wb}}$ ( $\mathrm{BC}$ from biomass burning emissions, mainly from domestic activities) remained nearly the same from January through the different LD periods until the beginning of May.

(5) During LD3-LD4 phases there is a steady decrease in both $\mathrm{BC}_{\mathrm{ff}}$ and $\mathrm{BC}_{\mathrm{wb}}$ in spite of relaxations and consequent increase in anthropogenic activities and vehicular traffic. This decrease has been due to washout of aerosols by the extensive precipitation that happened during LD3 and LD4 phases, which impacted both the carbonaceous species alike. This aspect is examined in detail in the last section of the article.

(6) Summarily, the LD restrictions imposed on vehicular traffic clearly manifest as a quick reduction in 
$>60 \%$ of the BC load in the atmosphere, which stayed so until the restrictions started reducing. On the other hand, the LD made no noticeable impact on $\mathrm{BC}_{\mathrm{wb}}$ concentrations and consequently the share of biomass burning (BB) to total $\mathrm{BC}$ increased during LD period.

The above observations unequivocally establish that the $\mathrm{BC}$ from vehicular emissions (including road, rail and air traffic) and from fossil fuel combustion contributes to more than $60 \%$ of the ambient $\mathrm{BC}$ load over Bengaluru.

\section{Impact on spectral absorption characteristics of BC}

It is well-established that the spectral variation of absorption coefficient of $\mathrm{BC}$ aerosols strongly depends on the composition and age of $\mathrm{BC}^{8,11,16}$. The spectral variation of $\mathrm{BC}$ absorption can be expressed by the simple Angstrom relation

$$
\beta_{\mathrm{abs}}(\lambda) \propto \lambda^{-\alpha_{\mathrm{abs}}},
$$

where $\beta_{\text {abs }}$ is the absorption coefficient at wavelength $\lambda$ and $\alpha_{\mathrm{abs}}$ is the absorption Angstrom exponent (AAE). For nascent BC emitted from fossil fuels (such as diesel burning), $\alpha_{\mathrm{abs}}$ is close to 1 , whereas for $\mathrm{BC}$ from pure biomass burning $\alpha_{\mathrm{abs}}$ would be close to 2 and for mixed $\mathrm{BC}$ the value lies in-between ${ }^{11,17}$. In Figure 4 , we present the time series of $\alpha_{\mathrm{abs}}$, calculated as the slope of the least square fitted (to eq. (1)) line to the absorption coefficients, deduced from the Aethalometer data as a function of wavelength (370-950 nm) in log-log scale, along with that of the biomass fraction $\left(\mathrm{BC}_{\mathrm{wb}} / \mathrm{BC}\right)$.

The figure clearly shows the nearly steady level of $\alpha_{\mathrm{abs}}$ during the pre-LD1 phase (superposed with fluctuations), an increasing trend during the mini-shutdown to a remarkable increase during LD1, during which $\alpha_{\text {abs }}$ increased from the low value of $<1.2$ to close to 1.5 and stayed around that level until 27 April, with little fluctua-

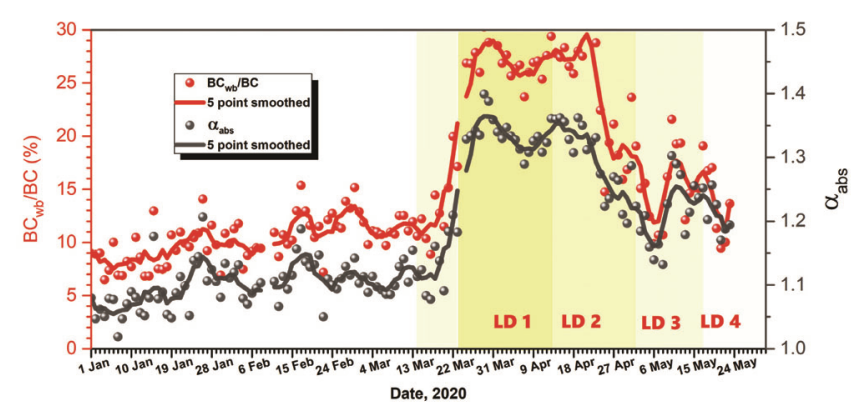

Figure 4. Time series of the daily mean values of biomass BC fraction (red colour) and the absorption Angstrom exponent (black colour). The continuous lines show the 5-point smoothed variations. tions. Subsequently, it started decreasing steadily and approached values close to the pre-LD values by midMay. This variation is clearly in-line with the variation of the $\mathrm{BB}$ fraction (ratio of biomass $\mathrm{BC}$ to $\mathrm{BC}$ estimated as $\mathrm{BC}_{\mathrm{wb}} / \mathrm{BC}$ ), thereby revealing the remarkable change in the absorbing property of the atmosphere with consequence on aerosol radiation forcing. The reduction in $\alpha_{\mathrm{abs}}$ and $\mathrm{BC}_{\mathrm{wb}}$ fraction during LD3 and LD4 is attributed to the precipitation during LD3/LD4 phases and are examined in a later section.

\section{Impact of scattering properties of composite aerosols}

Time series of total and back scattering coefficients (respectively denoted by $\beta_{\mathrm{st}}$ and $\beta_{\mathrm{sb}}$ ) at the three wavelengths (blue, green and red) measured by the integrating nephelometer and corrected for the angular truncation effects is shown in Figure $5\left(\beta_{\mathrm{st}}\right.$ and $\beta_{\mathrm{sb}}$ values were interpolated to 450,550 and $700 \mathrm{~nm}$ using Angstrom power-law rela$\operatorname{tion}^{18}$ ), in the top and bottom panels respectively. A break in the data is due to the instrument shutdown during the period from 24 March and 1 April, when the lab remained completely closed, with no access. The Aethalometer, however, continued operation without any interruption. Scattering arises from the composite aerosols, comprising both natural and anthropogenic species. The former comprises dust, biogenic aerosols from vegetation and secondary organic aerosols, whereas the latter comprises mainly of sulphates and nitrates from gas to particle conversion processes of anthropogenic emissions, soot and dust raised by traffic.

Figure 5 clearly shows that:

(1) From moderately high values prior to the LD period, both $\beta_{\mathrm{st}}$ and $\beta_{\mathrm{sb}}$ start decreasing right from the minishutdown phase from $14 \mathrm{March}$, and later reaches much lower values during the LD periods; the values being comparable to those generally reported for rural environments.

(2) The day-to-day variations and variations with longer periodicities that were conspicuous in the time series prior to LD phase, become highly subdued during the entire LD period, obviously due to large reduction in the variation of source strengths, mainly associated with traffic.

(3) Another interesting observation is that the scattering coefficients $\left(\beta_{\mathrm{st}}\right.$ and $\left.\beta_{\mathrm{sb}}\right)$ continue to decrease further from LD1 to LD2 to LD3 and do not show tendency to increase even after the end of the third phase of $\mathrm{LD}$, a feature which is contrary to that shown by BC in Figure 3. This shows the lesser efficacy of the relaxations on recharging the atmosphere with composite scattering aerosols, though BC started showing the effects right from LD2 onwards. The reasons 

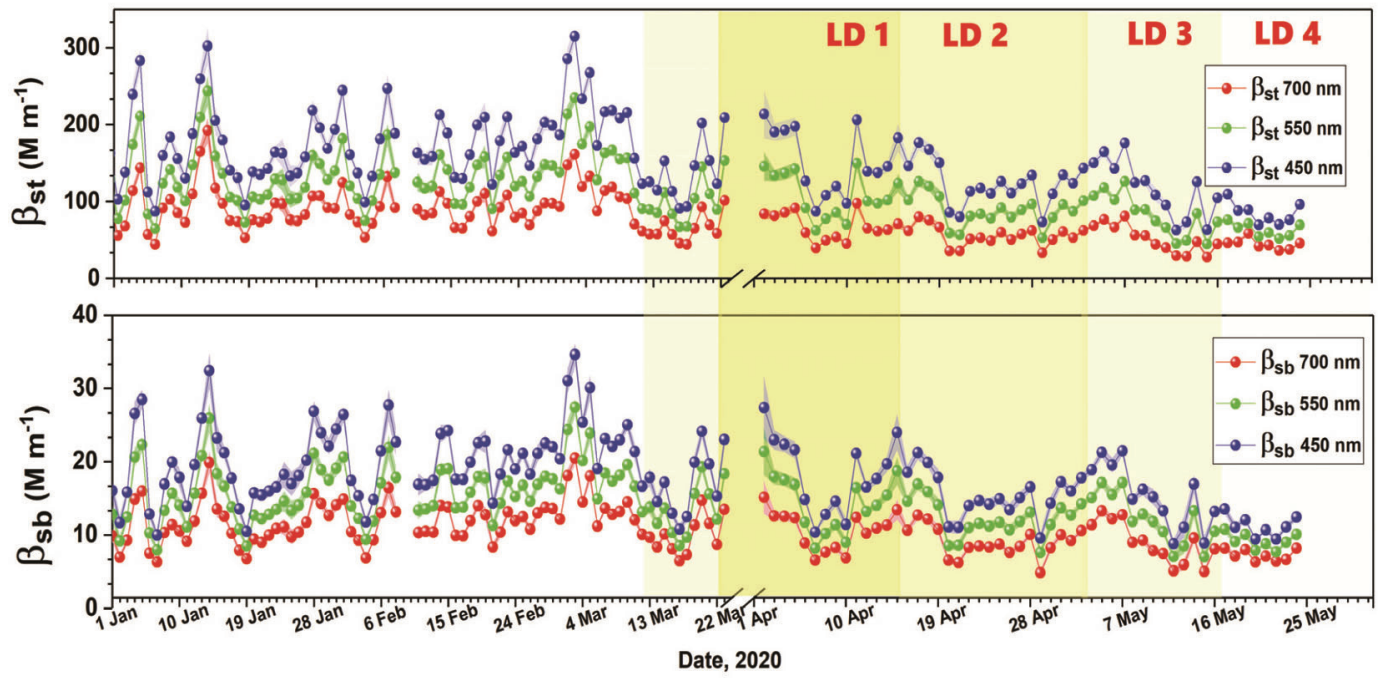

Figure 5. Time series of daily mean values of total scattering $\left(\beta_{\mathrm{st}}\right)$ in the top panel and back scattering coefficients $\left(\beta_{\mathrm{sb}}\right)$ in the bottom panel at different wavelengths. The data-break from 24 March to 1 April is due to instrument shutdown during the total closure of the laboratory during the initial phase of LD1. The Aethalometer observations, however, continued uninterrupted.
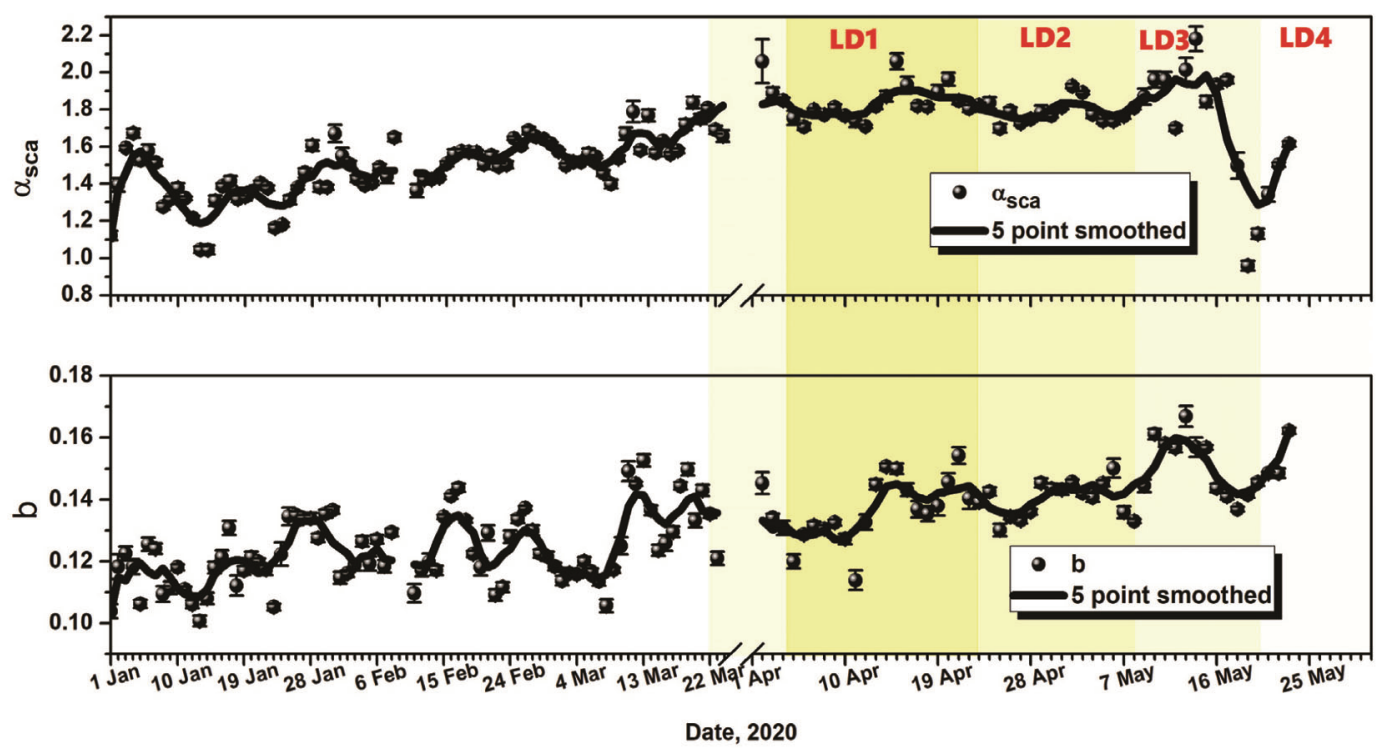

Figure 6. Time variation of the daily mean values scattering Angstrom exponent ( $\left.\alpha_{\text {sca }}\right)$ (top panel) and back scatter fraction $(b)$ in the bottom panel. The continuous lines show 5 -point smoothed variations.

for this (in terms of reduction in construction activities and time constants of gas phase reactions to form aerosols, etc.) needs separate study.

As the reduction in anthropogenic activities during the LD would impact different sources differently, it is possible that the size spectrum of aerosols would undergo relative changes. This is examined by plotting the time series of scattering Angstrom exponent $\alpha_{\text {sca }}$ in the relation

$$
\beta_{\mathrm{sca}}(\lambda) \propto \lambda^{-\alpha_{\mathrm{sca}}},
$$

where $\beta_{\text {sca }}$ is the scattering coefficient. $\alpha_{\text {sca }}$ is estimated for each measurement of the Nephelometer as the slope of the regression line connecting $\beta_{\text {sca }}(\lambda)$ and $\lambda$ in a $\log -\log$ scale and its variations are shown in Figure 6. The continuous lines show the 5-point running mean smoothed variations. It is clearly seen that from its value around 1.3 during January-February period, $\alpha_{\text {sca }}$ start increasing gradually from mid-March and then rather sharply with the commencement of the LD phases to reach values as high as 1.8 to 2 ; clearly implying increasing dominance of sub-micron sized particles (reduced coarse mode influence). The sharp fall in $\alpha_{\text {sca }}$ during 

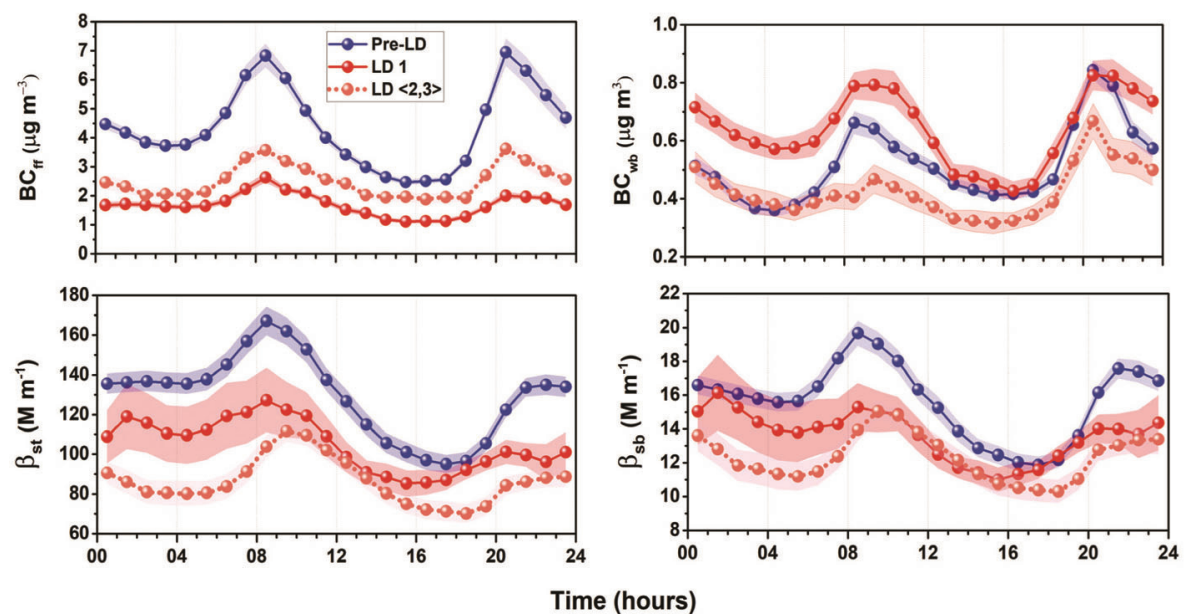

Figure 7. Average diurnal variations of $\mathrm{BC}_{\mathrm{ff}}, \mathrm{BC}_{\mathrm{wb}}, \beta_{\mathrm{st}}$ and $\beta_{\mathrm{sb}}$ during different periods: pre-lockdown (pre-LD) represented by blue colour, LD1 represented by red continuous lines and average for LD 2 and 3 phases, red dotted lines. The spheres represent the hourly averages for the respective period and the shaded areas denote respective standard errors.
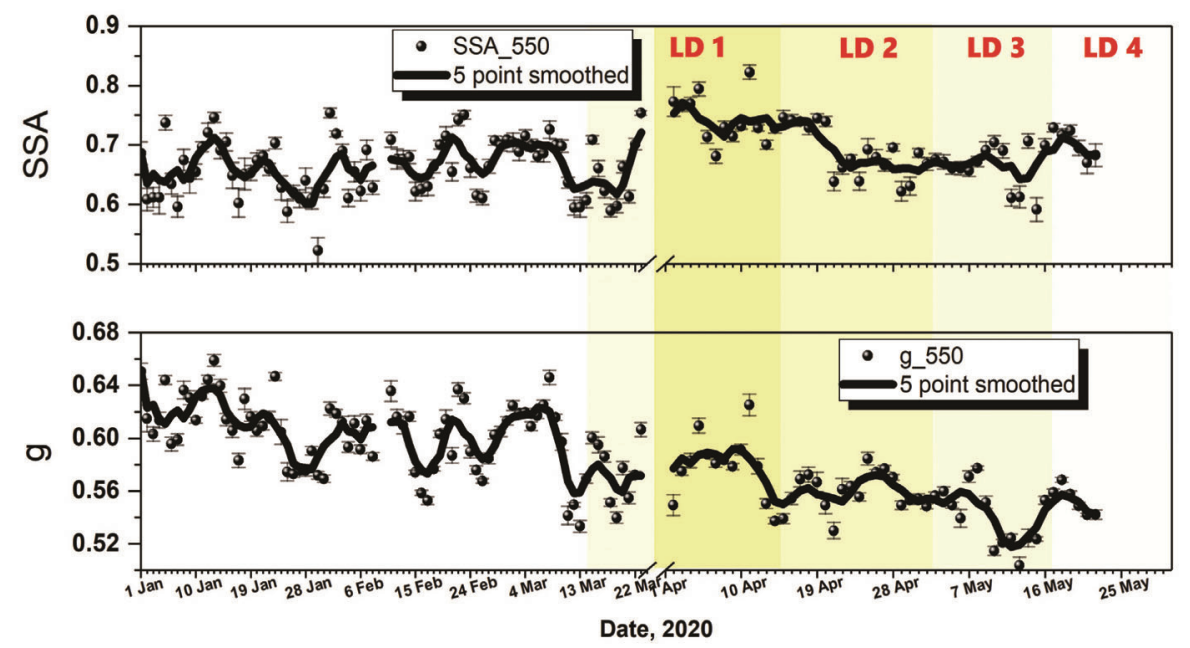

Figure 8. Time series of the daily mean (and standard error) of single scattering albedo (SSA) and asymmetry parameter $(g)$ at $550 \mathrm{~nm}$ wavelength. The continuous lines represent the 5-point smoothed variations.

LD3, as the case with other parameters discussed earlier, is associated with extensive rainfall and is examined in a later section.

The lower panel of Figure 6 showing the time series of back scatter fraction $b\left(=\beta_{\mathrm{sb}} / \beta_{\mathrm{st}}\right)$, smoothed using a 5point running mean filter, further substantiates the above. A steady increase in $b$ is noticeable from 14 March onwards, which continued well into LD3. From Mie scattering considerations, it is evident that increase in the back-scattering ratio is indicative of increasing dominance of accumulation and finer particles in the aerosol size spectrum. Thus, Figures 5 and 6 together reveal that not only the concentration of composite aerosols reduced greatly during lockdown, their size spectrum also shifted more towards accumulation regime (implying a reduction in the effective radius).

\section{Diurnal variations}

Concentrations as well as scattering and absorption coefficients of near-surface aerosols are known to depict well-resolved diurnal variations, which are attributed to the combined effects of the diurnal variation in the atmospheric boundary layer depth ${ }^{19-21}$ and ventilation coefficients and of the source strengths (for example change in traffic volume). Under normal conditions, it is difficult to separate these two effects. The near-cessation of traffic following the LD, especially in phase-1, provided an opportunity to delineate the relative roles of these two. In Figure 7, we have shown the mean diurnal variations of $\mathrm{BC}_{\mathrm{ff}}, \mathrm{BC}_{\mathrm{wb}}, \beta_{\mathrm{st}}, \beta_{\mathrm{sb}}$ for different periods; before the $\mathrm{LD}$, during the main phase LD1 and the relaxed phase $\operatorname{LD}\langle 2,3\rangle$. The figure clearly shows that the diurnal 
Table 1. Impact of the lockdown and its different phases on aerosol parameters at Bengaluru. The values are the mean for the period and the numbers appearing after \pm symbol are the corresponding standard errors

\begin{tabular}{|c|c|c|c|c|c|c|c|c|c|}
\hline Period & $\begin{array}{c}\mathrm{BC}_{\mathrm{ff}} \\
\left(\mu \mathrm{g} \mathrm{m}^{-3}\right)\end{array}$ & $\begin{array}{c}\mathrm{BC}_{\mathrm{wb}} \\
\left(\mu \mathrm{g} \mathrm{m}^{-3}\right)\end{array}$ & $\alpha_{\mathrm{abs}}$ & $\begin{array}{c}\beta_{\mathrm{st}} \\
\left(\mathrm{M} \mathrm{m}^{-1}\right)\end{array}$ & $\begin{array}{c}\beta_{\mathrm{sb}} \\
\left(\mathrm{M} \mathrm{m}^{-1}\right)\end{array}$ & $\alpha_{\text {sca }}$ & $b$ & $g$ & SSA \\
\hline $\begin{array}{l}\text { Normal pre- } \\
\text { LD (1 January } \\
\text { to } 23 \text { March) }\end{array}$ & $4.33 \pm 0.15$ & $0.51 \pm 0.02$ & $1.11 \pm 0.004$ & $130 \pm 4$ & $16 \pm 0.4$ & $1.49 \pm 0.02$ & $0.12 \pm 0.001$ & $0.601 \pm 0.003$ & $0.66 \pm 0.01$ \\
\hline $\begin{array}{l}\text { LD1 (24 Mar } \\
\text { to } 14 \text { April) }\end{array}$ & $1.69 \pm 0.04$ & $0.64 \pm 0.02$ & $1.34 \pm 0.006$ & $107 \pm 8$ & $14 \pm 1.1$ & $1.81 \pm 0.03$ & $0.13 \pm 0.003$ & $0.58 \pm 0.007$ & $0.74 \pm 0.005$ \\
\hline $\begin{array}{l}\text { LD2 (15 April } \\
\text { to } 3 \text { May) }\end{array}$ & $2.23 \pm 0.12$ & $0.66 \pm 0.03$ & $1.28 \pm 0.013$ & $90 \pm 5$ & $13 \pm 0.7$ & $1.84 \pm 0.02$ & $0.14 \pm 0.001$ & $0.56 \pm 0.003$ & $0.69 \pm 0.011$ \\
\hline $\begin{array}{l}\text { LD3 (4 May to } \\
17 \text { May) }\end{array}$ & $2.58 \pm 0.25$ & $0.43 \pm 0.03$ & $1.22 \pm 0.015$ & $82 \pm 7$ & $12 \pm 0.9$ & $1.87 \pm 0.04$ & $0.15 \pm 0.003$ & $0.54 \pm 0.006$ & $0.67 \pm 0.010$ \\
\hline $\begin{array}{l}\text { LD4 (18 May } \\
\text { to } 24 \text { May) }\end{array}$ & $1.88 \pm 0.09$ & $0.29 \pm 0.03$ & $1.21 \pm 0.011$ & $61 \pm 3$ & $9 \pm 0.4$ & $1.39 \pm 0.10$ & $0.15 \pm 0.003$ & $0.55 \pm 0.007$ & $0.69 \pm 0.012$ \\
\hline
\end{tabular}

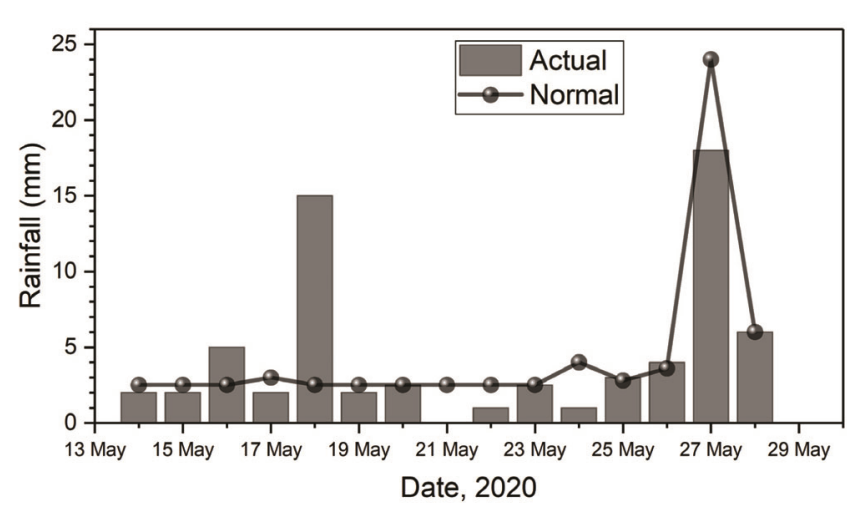

Figure 9. Daily rainfall South Interior Karnataka region which includes the study location also during 14 May to 28 May. Data from India Meteorological Department.

variations are almost unaffected by the LD, except for the overall reduction in amplitude of $\mathrm{BC}$ concentration and total scattering coefficient. This emphasizes the role of boundary layer dynamics rather than the temporal variation of human activities or source strengths, in producing the observed diurnal variations in aerosol concentration and properties.

\section{Intensive proprieties of aerosols}

Continuous and simultaneous measurements of absorption and scattering of aerosols enable us to derive some of the optical properties of aerosols such as SSA (single scattering albedo $=$ ratio of scattering coefficient to extinction coefficient) and $g$ (asymmetry parameter); both which are important in assessing the radiative impacts of aerosols. These are calculated using the following relations

$$
\operatorname{SSA}(\lambda)=\frac{\beta_{\mathrm{st}}(\lambda)}{\beta_{\mathrm{st}}(\lambda)+\sigma_{\mathrm{abs}}(\lambda)},
$$

$$
g=-7.143 * b^{3}+7.464 * b^{2}-3.963 * b+0.9893
$$

where $\beta_{\mathrm{st}}$ and $b$ are the scattering coefficients and back scatter fraction $\left(=\beta_{\mathrm{sb}} / \beta_{\mathrm{st}}\right)$. Equation for $g$ follows Andrews $^{22}$ based on Wiscombe ${ }^{23}$ following HenyeyGreenstein approximation for asymmetry parameter.

The time series of these two parameters, shown in Figure 8, clearly shows the impacts of LD and the subsequent relaxations. From the pre-LD prevailing value of $\sim 0.66$, SSA shot up to $\sim 0.74$ by first week of April, followed by gradual decrease to values close to 0.69 by mid-May. Similarly, $g$ decreased from around 0.6 to 0.55 , mostly due to decrease in the effective radius of the aerosol size spectrum (attributable to decrease in coarse mode abundance; probably traffic-related dust; however, this aspect needs independent measurements for confirmation). Our findings on the lockdown impact is summarized in Table 1.

An interesting observation from the Table is that, despite a fair amount of relaxations on restrictions on vehicular movement and human activities, there is a significant decrease in most of the aerosol parameters during the 4th phase of the LD (LD4) as shown by the values in its last row. This is attributed to extensive precipitation events since 14 May and is examined in detail below.

\section{Washout by precipitation}

To investigate the effects of local meteorology for this, we studied the rainfall data from the India Meteorological Department, averaged for South Interior Karnataka, which includes the measurement site also. The time series of the daily total rainfall for the period 14 May to 28 May is shown in Figure 9 by the vertical bars. The normal for these days, is shown by the line joining the points.

Figure 9 shows continuous rainfall during this period (with a couple of strong spells); the intensity of which was felt much stronger in the city (though no data available to 
substantiate due to LD). It appears that the extensive washout by these strong precipitations has led to lower the aerosol abundance during this phase. It is more evident from the observation that this decrease due to washout has impacted all aerosol species equally (even $\mathrm{BC}$ from wood burning) unlike the LD phases, which impacted the anthropogenic emissions selectively. Consequently, though the absorption and scattering coefficients decreased responding to the precipitation, the SSA remained lower than its value during LD1.

\section{Conclusion}

An unprecedented, and probably once in a lifetime, prolonged LD of human activities as a result of the COVID19 pandemic provided a unique opportunity to study the consequence on regional environment and assess the anthropogenic contributions, using primary measurement data. Our study from Bengaluru has shown:

(1) A remarkable reduction in the concentration of aerosols, especially fossil fuel black carbon (road, rail and flight), associated with the LD. During the main LD phase (LD1), BC concentration from fossil fuel emissions (in the local situation from vehicular exhaust) decreased by $>60 \%$ of the average value that prevailed prior to LD and became comparable to those seen at remote rural location. It recovered gradually during the subsequent phases of the LD, in-line with the gradual and stepwise relaxation of the restrictions on traffic. This observation establishes the role of aerosols from vehicular/traffic (including road, rail and air) as the single major contributor to elevated $\mathrm{BC}$ levels at Bengaluru.

(2) The concentration of BC from biomass burning (associated mainly with domestic activities) remained nearly steady during the entire period, almost unaffected by the LD.

(3) Consequently, the spectral absorption of $\mathrm{BC}$ became steeper initially and then started flattening during the later stages.

(4) Composite aerosol scattering coefficient showed a gradual decrease, primarily due to the decrease in concentration of aerosols. The spectral dependency became steeper suggesting an increasing abundance of accumulation and fine mode particles. In-line with this, the backscatter fraction showed a steady and gradual increase.

(5) Aerosol single scatter albedo increased by nearly $20 \%$ during LD1 and started decreasing slowly in the subsequent phases as emission of $\mathrm{BC}$ started increasing with relaxation in restrictions on vehicular movement.

(6) Backscatter fraction increased gradually through the LD phases, implying increasing sub-micron aerosol abundance in the size spectrum.
(7) Significant precipitation during the LD3/LD4 period caused substantial and non-selective reduction in all aerosol parameters during LD4, which stood in contrast to the changes seen in LD1. As washout is nonselective of aerosol types, the reduction occurred in the concentration of all the species almost uniformly and consequently the SSA remained unaffected, unlike in LD1 when only the anthropogenic contributions were curtailed and SSA increased.

(8) Our study showed clearly that aerosols associated with vehicular traffic contributes to $>60 \%$ of the concentration of aerosols, especially $\mathrm{BC}_{\mathrm{ff}}$ aerosols in Bengaluru, and once these are stopped, the environment of Bengaluru becomes comparable to that of a remote rural location.

1. IPCC, Climate Change 2013: The Physical Science Basis. Contribution of Working Group I to the Fifth Assessment Report of the Intergovernmental Panel on Climate Change (eds Stocker, T., Dahe, Q. and Plattner, G.-K.), Cambridge University Press, Cambridge, 2013.

2. Jacobson, M. Z., Control of fossil-fuel particulate black carbon and organic matter, possibly the most effective method of slowing global warming. J. Geophys. Res., 2002, 107(D19), 4410; http://dx.doi.org/10.1029/2001JD001376.

3. Ramanathan, V. and Carmichael, G., Global and regional climate changes due to black carbon. Nature, 2008, 221-227; http://dx. doi.org/10.1038/ngeo156.

4. Babu, S. S. and Moorthy, K. K., Aerosol black carbon over a tropical coastal station in India. Geophys. Res. Lett., 2002, 29(23), 13-11-13-14; doi:10.1029/2002g1015662.

5. Latha, K., Badrinath, K. V. S. and Moorthy, K. K., Impact of diesel vehicular emissions on ambient black carbon concentration at an urban location in India. Curr. Sci., 2004, 86(3), 451-453.

6. Satheesh, S. K., Vinoj, V. and Moorthy, K. K., Weekly periodicities of aerosol properties observed at an urban location in India. Atmos. Res., 2011, 101(1-2), 307-313; doi:10.1016/j.atmosres. 2011.03.003.

7. Hansen, A. D. A., Rosen, H. and Novakov, T., The aethalometer an instrument for the real-time measurement of optical absorption by aerosol particles. Sci. Total Environ., 1984, 36, 191-196.

8. Sandradewi, J., Prévôt, A. S. H., Weingartner, E., Schmidhauser, R., Gysel, M. and Altensperger, U., A study of wood burning and traffic aerosols in an Alpine valley using a multi-wavelength aethalometer. Atmos. Environ., 2008, 42, 101-112.

9. Drinovec, L., Močnik, G., Zotter, P., Prévôt, A. S. H., Ruckstuhl, C., Coz, E. and Hansen, A. D. A., The 'dual-spot' Aethalometer: an improved measurement of aerosol black carbon with real-time loading compensation. Atmos. Meas. Tech., 2015, 8(5), 19651979; doi:10.5194/amt-8-1965-2015.

10. Weingartner, E., Saathoff, H., Schnaiter, M., Streit, N., Bitnar, B. and Baltensperger, U., Absorption of light by soot particles: determination of the absorption coefficient by means of aethalometers. $J$. Aerosol Sci., 2003, 34(10), 1445-1463; doi:10.1016/s00218502(03)00359-8.

11. Kirchstetter, T. W., Novakov, T. and Hobbs, P. V., Evidence that the spectral dependence of light absorption by aerosols is affected by organic carbon. J. Geophys. Res.: Atmosphere, 2004, 109(D21); http://dx.doi.org/10.1029/2004JD004999.

12. Kleidman, R., Martins, J. V., Townsend, H. K., Hall, J., Gibson, M. D. and Martin, R., New capability for in situ measurements of particulate matter using size-selecting nephelometers as part of the SPARTAN network. Paper presented at the AGU Fall Meeting 
Abstracts, 2018; https://ui.adsabs.harvard.edu/abs/2018AGUFM. A $1312558 \mathrm{~K}$

13. Anderson, T. L. and Ogren, J. A., Determining aerosol radiative properties using the TSI 3563 integrating nephelometer. Aerosol Sci. Technol., 1998, 29(1), 57-69; doi:10.1080/02786829808965551 .

14. Jethva, H. T., Satheesh, S. K., Srinivasan, J. and Krishnamoorthy, $\mathrm{K}$., How good is the assumption about visible surface reflectance in MODIS aerosol retrieval over land? A comparison with aircraft measurements over an urban site in India. IEEE Trans. Geosci. Rem. Sens., 2009, 47(7), 10.1109/TGRS.2008.2010221.

15. Anand, N., Sunilkumar, K., Satheesh, S. K. and Krishna Moorthy, K., Entanglement of near-surface optical turbulence to atmospheric boundary layer dynamics and particulate concentration: implications for optical wireless communication systems. Appl. Opt., 2020, 59(5), 1471; doi:10.1364/ao.381737.

16. Moosmüller, H., Chakrabarty, R. K., Ehlers, K. M. and Arnott, W. P., Absorption Ångström coefficient, brown carbon, and aerosols: basic concepts, bulk matter, and spherical particles. Atmos. Chem. Phys., 2011, 11(3), 1217-1225; doi:10.5194/acp-11-1217-2011.

17. Sandradewi, J. et al., Using aerosol light absorption measurements for the quantitative determination of wood burning and traffic emission contributions to particulate matter. Environ. Sci. Technol., 2008, 42, 3316-3323; doi:10.1021/es702253m.
18. Ångström, A., The parameters of atmospheric turbidity. Tellus, 1964, 16, 64-75.

19. Stull, R. B., An Introduction to Boundary Layer Meteorology, Kluwer, Dordrecht, 1988, p. 666; http://dx.doi.org/10.1007/97894-009-3027-8

20. Babu, S. S. and Moorthy, K. K., Anthropogenic impact on aerosol black carbon mass concentration at a tropical coastal station: a case study. Curr. Sci., 2001, 81(9), 1208-1214.

21. Nair, V. S. et al., Wintertime aerosol characteristics over the IndoGangetic Plain (IGP): impacts of local boundary layer processes and long-range transport. J. Geophys. Res., 2007, 112, D13205; http://dx.doi.org/10.1029/2006 JD008099.

22. Andrews, E. et al., Comparison of methods for deriving aerosol asymmetry parameter. J. Geophys. Res., 2006, 111, D05S04; doi:10.1029/2004JD005734

23. Wiscombe, W. J. and Grams, G., The backscattered fraction in two-stream approximations. J. Atmos. Sci., 1976, 33, 2440e2451.

ACKNOWLEDGEMENTS. We thank the Aerosol lab project team from Indian Institute of Science, Bengaluru campus for data collection. We gratefully acknowledge Divecha Centre for Climate Change for supporting this work.

doi: $10.18520 / \mathrm{cs} / \mathrm{v} 120 / \mathrm{i} 2 / 287-295$ 